\title{
Defective Candida killing in childhood malnutrition
}

\author{
ROGER TUCK, VALERIE BURKE, MICHAEL GRACEY, ANNE MALAJCZUK, AND \\ SUNOTO \\ The Regional Hospital, Derby and Princess Margaret Children's Medical Research Foundation, \\ Perth, Western Australia, and the Department of Child Health, University of Indonesia, Jakarta
}

SUMMARY This study shows that malnourished children have impaired candidacidal activity of leucocytes, a finding which runs parallel to the higher rates of isolation of Candida sp. from throat secretions. In well nourished subjects the mean candidacidal ability was $44.5 \%$, in the moderately undernourished group it was $17.6 \%$, and in the severely malnourished group it was $13.7 \%$. This impaired candidacidal capacity may be important in the establishment of large numbers of Candida $\mathrm{sp}$. which are commonly found in the upper intestine and in the pathogenesis of diarrhoea in children with malnutrition.

Candida species are common in the upper intestinal contents of malnourished children (Mata et al., 1972; Gracey et al., 1974) and may contribute to the production of diarrhoea by their effects on intestinal absorption of sugar (Burke et al., 1977) and water (Thelen et al., 1978). The mechanism by which such large numbers of Candida become established in malnourished children is not clear. Previous studies have shown the ability of such children to secrete intestinal immunoglobulins to be unimpaired (Bell et al., 1976), while depression of cell-mediated immunity in vivo and in vitro has been reported in malnutrition (Geefhuysen et al., 1971; Chandra, 1972; Ferguson et al., 1974). However Kulapongs et al. (1974) found lymphocyte responsiveness to phytohaemagglutinin and killing ability of polymorphs to be normal in a group of malnourished children with iron deficiency, while Macdougall et al. (1975) found cell-mediated immunity was impaired in such children. Bactericidal function of polymorphs was assessed using Escherichia coli as the test organism in the study of Kulapongs et al. (1974), but Macdougall et al. (1975) and other investigators, showing impaired killing ability of polymorphs (Seth and Chandra, 1972), used staphy-

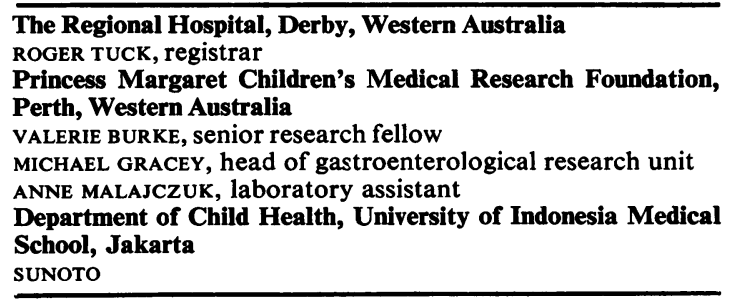

lococci. It may be that bactericidal function is reduced only in relation to specific organisms.

Lehrer and Cline (1969) showed that leucocytic function was important in resistance to Candida infection. Using their technique, it was shown that the Candida-killing ability of polymorphs is reduced in newborn babies, a group known to be susceptible to mucosal candidal infections (Xanthou et al., 1975). Because of our interest in gastrointestinal candidiasis in malnourished children we investigated the Candida-killing ability of polymorphs in such children.

\section{Materials and methods}

Patients. Blood and throat swabs were obtained from 67 children and adults. Patients were classified according to the recommendations of the Wellcome Working Party (Lancet, 1970) into a normal group with body weights $>80 \%$ standard weight for age (SWFA), an underweight group 60-80\% SWFA, and a marasmic group $<60 \%$ SWFA. Samples of $4 \mathrm{ml}$ heparinised blood were obtained by venepuncture from normal adults, well nourished children without known immunological deficiencies attending Princess Margaret Hospital in Perth, Indonesian children admitted to hospital in Jakarta, and from Australian aboriginal children in hospital in Derby, an isolated country town on the coast in the far north of Western Australia.

Candida-killing ability of leucocytes. The method of Lehrer and Cline (1969) was used with the modifications of Xanthou et al. (1975) to minimise the volume of blood taken from the children. Killing 
ability was measured by counting the number of Candida stained by methylene blue which distinguishes killed organisms, after incubating comparable nnmbers of neutrophils and viable Candida in serum with Hanks's solution for 30 minutes at $37^{\circ} \mathrm{C}$. All tests were done using patients' sera as well as with normal adult sera. At least 300 cells were counted for each sample and results are expressed as the number killed-that is, blue-stained Candida/ 100 phagocytosed organisms. Differences in percentage of Candida killed in groups classified according to nutritional status were assessed using the Kolmogorov-Smirnov test.

Throat swabs. Specimens were collected into Stuart's transport medium and refrigerated at $4^{\circ} \mathrm{C}$ if not processed immediately. Those from Derby and Jakarta were flown to Perth on ice and processed within 24 hours of collection. Throat swabs were cultured in Sabouraud's dextrose agar and incubated for 48 hours at $25^{\circ} \mathrm{C}$.

\section{Results}

Candida-killing ability was not related to age, race, or diagnosis on admission to hospital. Consequently, results were considered only in relation to the patient's nutritional state.

In the well nourished group the mean candidacidal ability was $44 \cdot 5 \%$ (SEM $8 \cdot 8)$, for those with weights $60-80 \%$ SWFA the mean was $17 \cdot 6 \%$ (SEM 4.4), and for children with weights $<60 \%$ of SWFA the mean was $13 \cdot 7 \%$ (SEM 3.4). Results are shown in the Figure. Comparison of each malnourished group with the well nourished subjects showed the difference to be highly significant $(P<0 \cdot 001)$. However, there was no significant difference in candidacidal ability between the two groups of malnourished children. Addition of normal sera in place of the patients' own sera did not alter the Candida-killing ability of their leucocytes.

We previously showed (Gracey et al., 1973) that oropharyngeal flora probably reflect environmental contamination, so that it is invalid to compare isolation rates of organisms from such different areas as Perth, Derby, and Jakarta. As there were no malnourished children from Perth, results of throat swabs taken in Perth were not included in the analysis. Children from Derby and Jakarta were grouped according to nutritional status and separate comparisons made for each area. In Jakarta, $92 \%$ of malnourished children had Candida in their throat swabs compared with $66 \%$ of normal children; in Derby Candida was grown from throat swabs of $80 \%$

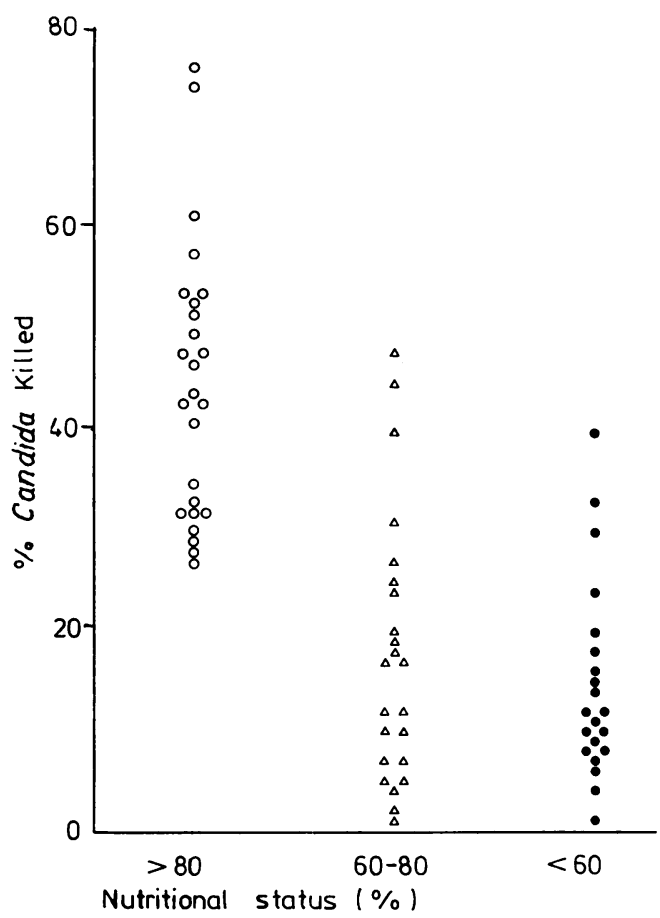

Figure Candida-killing capacity (expressed as percentage of Candida killed) according to nutritional status expressed as a percentage of standard weight for age compared with the 50th centile of the Harvard standards (Lancet, 1970).

of malnourished children but from only $14 \%$ of normal children.

\section{Discussion}

We show that malnourished children have reduced candidacidal activity of their leucocytes. This finding runs parallel to the higher isolation rate of Candida sp. from throat swabs of malnourished children. The defective Candida-killing ability of these leucocytes was not corrected by adding normal serum. Lehrer and Cline (1969) found that serum factors did not affect the candidacidal property of leucocytes and the addition of normal serum did not correct defective Candida-killing by leucocytes in the newborn (Xanthou et al., 1975). It would seem that malnourished children also have impaired leucocyte function in relation to Candida killing. We found that the Candida-killing ability of leucocytes was reduced in patients with a high isolation rate of Candida sp. from their throat swabs. Organisms isolated from the upper small bowel are similar to the flora of the oral cavity (Dickman et al., 1976) and our previous investigations suggest that Candida sp. 
are likely to be found in the upper intestinal contents of these children (Gracey et al., 1974). The relationship between gastrointestinal infection with Candida sp. and impaired Candida-killing ability of leucocytes is not clear. Although several investigators have established the importance of intestinal antibodies in controlling bacterial contamination of the upper intestinal contents (Walker and Isselbacher, 1977), their role in relation to intestinal candidiasis is not known. However, malnutrition does not impair secretion of immunoglobulins into the intestinal lumen as intestinal immunoglobulin levels have been shown to be raised in malnourished children with infections (Bell et al., 1976). The importance of leucocytic function in maintaining the relative sterility of upper intestinal contents has not been widely investigated. However Takeuchi et al. (1965) and Kenworthy (1970) showed that phagocytosis was important during the establishment of experimental infections with Shigella and E. coli. It may be that neutrophils are also important in controlling candidal infections in the small intestine.

Our findings show that polymorphs from malnourished children have an impaired ability to kill Candida and extend the observation that the ability to kill Staphylococcus pyogenes is reduced in malnutrition (Seth and Chandra, 1972). This mechanism may contribute to the significantly increased incidence of candidal infections in malnourished children.

We thank everyone in Australia and Indonesia who took part in this study, and the doctors and nurses who helped to collect and transport the specimens.

R.T. was seconded from the Princess Margaret Hospital for Children, Perth, Western Australia.

\section{References}

Bell, R. G., Turner, K. J., Gracey, M., Suharjono, and Sunoto (1976). Serum and small intestinal immunoglobulin levels in undernourished children. American Journal of Clinical Nutrition, 29, 392-397.

Burke, V., Houghton, M., and Gracey, M. (1977). Effect of enteric micro-organisms on intestinal sugar and fatty acid absorption. Australian Journal of Experimental Biology and Medical Science, 55, 423-429.

Chandra, R. K. (1972). Immuno-competence in undernutrition. Journal of Pediatrics, 81, 1194-1200.

Dickman, M. D., Chappelka, A. R., and Schaedler, R. W. (1976). The microbial ecology of the upper small bowel. American Journal of Gastroenterology, 65, 57-62.

Ferguson, A. C., Lawlor, G. J., Jr, Neumann, C. G., Oh, W., and Steihm, E. R. (1974). Decreased rosette-forming lymphocytes in malnutrition and intrauterine growth retardation. Journal of Pediatrics, 85, 717-723.

Geefhuysen, J., Rosen, E. V., Katz, J., Ipp, T., and Metz, J. (1971). Impaired cellular immunity in kwashiorkor with improvement after therapy. British Medical Journal, 4, 527-529.

Gracey, M., Stone, D. E., Suharjono, and Sunoto (1973). Oropharyngeal microflora in malnourished children. Australian Paediatric Journal, 9, 260-262.

Gracey, M., Stone, D. E., Suharjono, and Sunoto (1974). Isolation of Candida species from the gastrointestinal tract in malnourished children. American Journal of Clinical Nutrition, 27, 345-349.

Kenworthy, R. (1970). Effect of Escherichia coli on germ-free and gnotobiotic pigs. I. Light and electron microscopy of the small intestine. Journal of Comparative Pathology, 80, 53-63.

Kulapongs, P., Vithayasai, V., Suskind, R., and Olson, R. E. (1974). Cell-mediated immunity and phagocytosis and killing function in children with severe iron deficiency anaemia. Lancet, 2, 689-691.

Lancet (1970). Editorial: Classification of infantile malnutrition. Lancet, 2, 302-303.

Lehrer, R. J., and Cline, M. J. (1969). Interaction of Candida albicans with human leucocytes and serum. Journal of Bacteriology, 98, 996-1004.

Macdougall, L. G., Anderson, R., McNab, G. M., and Katz, J. (1975). The immune response in iron-deficient children: impaired cellular defense mechanisms with altered humoral components. Journal of Pediatrics, 86, 833-843.

Mata. L. J., Jimenez, F., Cordon, M., Rosales, R., Prera, E., Schneider, R. E., and Viteri, F. (1972). Gastrointestinal flora of children with protein-calorie malnutrition. American Journal of Clinical Nutrition. 25, 1118-1126.

Seth, V., and Chandra, R. K. (1972). Opsonin activity phagocytosis and bactericidal capacity of polymorphs in undernutrition. Archives of Disease in Childhood, 47, 282-284.

Takeuchi, A., Sprinz, H., LaBrec, E. H., and Formal, S. B. (1965). Experimental bacillary dysentery. An electron microscopic study of the response of the intestinal mucosa to bacterial invasion. American Journal of Pathology, 47, 1011-1044.

Thelen, P., Burke, V., and Gracey, M. (1978). Effects of intestinal micro-organsims on fluid and electrolyte transport in the jejunum of the rat. Journal of Medical Microbiology, 11, 463-470.

Walker, W. A., and Isselbacher, K. J. (1977). Intestinal antibodies. New England Journal of Medicine, 297, 767-773.

Xanthou, M., Valassi-Adam, E., Knitzonidou, E., and Matsanotis, N. (1975). Phagocytosis and killing ability of Candida albicans by blood leucocytes of healthy term and preterm babies. Archives of Disease in Childhood, 50, 72-75.

Correspondence to Dr Michael Gracey, Princess Margaret Children's Medical Research Foundation, Gastroenterological Research Unit, GPO Box D184, Perth 6001, Western Australia.

Received 12 September 1978 